\title{
A arte, entre a festa e a mudez
}

"Estética relacional" ou "arte da pós-produção" são expressões empregadas por Nicolas Bourriaud para caracterizar uma série de intervenções artísticas contemporâneas, correspondentes a um mundo crescentemente globalizado e informatizado ${ }^{1}$. Tais tendências de intervenção artística mereceram a atenção de Hal Foster, para quem obras delas representativas, "a meio caminho entre a instalação pública, a performance sombria e o arquivo privado", não deixam de assinalar "um giro distintivo da arte recente" . Em termos gerais, essa reviravolta é identificada, sobretudo, em operações artísticas resultantes de um trabalho de "manipulação secundária" de materiais pré-existentes (através de processos de seleção, combinação e edição, de corte e montagem, realizados a partir de imagens, textos, sons e outros resíduos imediatamente disponíveis no enorme arquivo informático, processos esses que radicalizam a prática ready-made), que em conjunto definiriam os contornos de "um novo estatuto da arte na era da informação", sucedânea da era da produção. Trata-se, como a denomina Foster, e não sem uma fina e ferina ironia, de uma "arte festiva" ("Artsy party", em inglês), na qual predomina uma "promiscuidade de colaborações", uma "interatividade feliz" que, por sua vez, leva a um questionamento das noções de autoridade e originalidade, tão caras aos hoje clássicos modernos. Uma arte do dom ou da oferta, em que algo compartilhado (convivências e encontros, inclusive com outros discursos) demanda ou motiva uma participação coletiva, a formação de uma comunidade que se reúne tanto a fim de dar a ver quanto de se dar a ver, mostrar e mostrar-se. Nela discursividade e sociabilidade se conjugam seja nos processos de criação, seja nos de exposição, e revelam uma certa disposição em valorizar o cotidiano e uma postura ética (que se traduz especialmente por uma crítica, não raro ambígua, ao capitalismo global e ao consumismo). Embora perceba na arte festiva a abertura de possibilidades pertinentes, Foster não deixa de criticá-la, sobretudo em função de uma certa postura
1. BOURRIAUD, Nicolas. Estética Relacional. São Paulo: Martins Fontes, 2009; Pós-produção: como a arte reprograma o mundo contemporâneo. São Paulo: Martins Fontes, 2009.

2. Em "Arte festiva", texto publicado na edição de ${ }^{\circ} 6$, de 2005, de Otra parte, revista dirigida por Graciela Speranza e Marcelo Cohen, e que pode ser acessado no endereço www. revistaotraparte.com/node/403, de onde provêm os fragmentos aqui citados. 
3. LADDAGA, Reinaldo. Estética de la emergencia. Buenos Aires: Adriana Hidalgo, 2006, p. 9. Tradução nossa, como de todos os trechos desse livro citados em diante. ingênua, que corre o risco de se transformar em um elogio mais ou menos implícito à sociedade de mercado e, ainda, na assunção de analogias pouco exigentes acerca das complexas relações entre a "pós-produção artística" e a produção social, ou seja, entre o domínio da estética e o da biopolítica. Como assinala Foster, a arte reclama tomadas de posição, o que só pode ser feito através da conjugação, nos e com os objetos artísticos, de uma perspectiva a um só tempo crítica, estética e epistemológica, com o que se torna para ela possível "contestar o caráter informe da sociedade ao invés de celebrá-lo, reconfigurando-o de uma forma que movimente a reflexão e a resistência".

Associatividade e discursividade são parâmetros também privilegiados por Reinaldo Laddaga em sua reflexão sobre a "formação de outra cultura das artes", subtítulo de Estética de la emergencia (2009), livro em que discute o trabalho de alguns artistas contemporâneos que do mesmo modo embasam o ensaio de Hal Foster (como o de Rirkrit Tiravanija ou o de Thomas Hischhorn, embora o autor privilegie produções coletivas, resultantes da participação em redes ou agrupamentos). Laddaga parte da hipótese de que experimentamos no presente uma mudança na cultura das artes comparável, segundo ele, àquela ocorrida entre o final do século XVIII e meados do século XIX, período em que emerge a configuração cultural da modernidade estética, ou do "regime estético da arte", como a denomina Jacques Rancière em seu Aisthesis (2011). Segundo Laddaga essa configuração cultural começou a entrar em crise nas últimas décadas do século passado, juntamente com formas típicas de organização e associação do capitalismo industrial e do Estado nacional (expressões da modernidade "disciplinaria", conceito que o autor busca em Foucault), quando artistas e escritores começaram a "se interessar menos em construir obras do que em participar na formação de ecologias culturais" ". Trata-se, então, para ele, de um verdadeiro "esgotamento do paradigma moderno", um sintoma da globalização, que, ao mesmo tempo, indica a insuficiência de práticas e posturas artísticas e culturais do chamado pós-modernismo. O silêncio tradicionalmente exigido pela recepção da obra de arte moderna cede lugar, em razão deste esgotamento, a uma sorte de estupefação muda quando nos colocamos, como sublinha o autor, diante dos projetos artísticos por ele analisados, que nos abre um universo ainda desconhecido: "Não sabemos verdadeiramente como falar de projetos... irreconhecíveis desde a perspectiva das disciplinas — nem produções de 'arte visual', nem de 'música', nem de 'literatura'- que, no entanto, inequivocamente se encontram na sua descendência; produções que tornam difícil decidir a que tradição nacional ou continental pertencem — se se trata de arte 'argentina', 'americana' ou 'francesa'- e que, todavia, colocam em questão a relação entre a produção de representações e de imagens e as formas de 
cidadania, só que agora em mais de uma língua, em mais de uma tradição, em mais de um lugar"'.

Precisamente pensando em discussões relativas à situação da arte e da cultura contemporâneas, elegemos o trecho de Los Fantasmas (1990), de César Aira, que precede esta apresentação -romance que, em breve, aparecerá publicado pela Editora Rocco, no Rio de Janeiro, em tradução de Jorge Wolff. Para nós, essa roupagem airada -que se complementa com as imagens de Max Cachimba que compõem a capa e a contracapa deste número, tomadas de Dante y Reina (2009) - é ideal para a temática que orienta os textos aqui reunidos, dedicados todos eles a manifestações coletivas da arte, ou a produções que fazem do convívio e, por que não, da confrontação, princípios de ativação dos seus procedimentos. Pelo mesmo motivo, incluímos neste número o $4^{\circ}$ capítulo de L'homme et le sacré, "O sagrado de transgressão: Teoria da festa", seguido do apêndice "Guerra e sagrado", que Roger Caillois publicara em 1939 como uma extensão dos seus estudos sobre o dom e o dispêndio. Além dessa tradução de Carlos Eduardo Schmidt Capela, recebemos a contribuição de Vinícius Nicastro Honesko e Fernando Scheibe, que traduziram a "Leitura do 'Batean ivre' de Rimbaud", publicada por Furio Jesi em 1972. Nesse ensaio -dedicado, entre outras coisas, a uma produção coletiva fundamental- Jesi pensa o toque, ou seja, o interdito pela própria essência "separada" do mito, como uma alternativa à máquina mitológica, cujo maior subterfúgio é se postular como portadora de uma verdade nuclear, uma substância, um centro. Perante essa essencialidade vazia, postula Jesi em sua leitura do poema de Rimbaud, não há uma autêntica alternativa conceitual, mas apenas alternativas gestuais, que da revolução à revolta, se articulam como derivas diversas em torno de um tempo que tem a potência de permitir uma passagem do lugar comum ao lugar do comum. Como complemento dessa leitura escrita, Vinícius Honesko disponibilizou para este número a sua tradução de "O talismã de Furio Jesi"(1996), do filósofo italiano Giorgio Agamben; e Carlos Eduardo Capela traduziu o próprio poema de Rimbaud.

Como produções artísticas e culturais não mais centradas na figura do artista, mas propondo-se como coletivos de produção, entre a festa e a mudez, diversas abordagens encaram essa "arte de mais de um", ora como reviravolta estética, ora como procura de outras formas de comunidade, ora como origem de células de rebelião. A proposta deste número da outra travessia foi pensar as práticas coletivas contemporâneas, nas suas dimensões estéticas e políticas, ou estéticas porque políticas, num amplo leque que, para além desses coletivos, também abordasse o próprio pensamento sobre o coletivo. Em resposta a esse chamado, recebemos contribuições que vale a pena mencionar brevemente. 
Em "arte Rorschach", Artur de Vargas Giorgi aborda o chamado informalismo, que a partir da década de 1950 reuniu uma espécie de comunidade contingente, quer dizer, não necessariamente coesa ou homogênea, de artistas. No ensaio, Vargas Giorgi analisa os avatares, contratempos e ressonâncias desse coletivo, das suas leituras críticas às suas manifestações pluralistas, e traça uma vasta cartografia, que inclui cidades como Buenos Aires, Rio de Janeiro e São Paulo.

"O convívio da poesia", de Luciana di Leone, problematiza, em relação com produções contemporâneas pautadas pela amizade, a noção de convívio, não raramente associada à poesia doméstica ou circunstancial. Como di Leone desenvolve, é precisamente a partir desse tipo de produção que se pode pensar numa poesia fora dos dispositivos de consciência, sujeito, ou autonomia, possibilitando outro tipo de trocas e valorações, mas também se abrem perigos inerentes à dimensão convivial, cuja celebração sem fissuras pode pacificar ou domesticar contrastes que fazem a pluralidade constituinte de toda arte.

Em "Dilemas da arte colaborativa: nomadismos, nivelamento relacional e coletividades", Marcelo Wasem analisa um diferenciado regime estético, que pela sua própria singularidade plural modifica as relações entre artista e público. Como ainda desenvolve este artigo, essa arte amplia a sua potência à medida que está à escuta de vozes coletivas, e faz da errância, da desterritorialização, e de um desejo sempre em movimento, a sua especial oikonomia poética.

Laura Maccioni e Gabriel Loyber, em "Redes colaborativas entre colectivos culturales y redefinición de la comunidad: el caso de la lucha por la derogación del Código de Faltas en Córdoba, Argentina”, examina as práticas colaborativas de um conjunto de coletivos que, através de sua produção em rede, desmontam e remontam códigos culturais, dispositivos e disciplinas. Esses coletivos, como explicam Loyber e Maccioni, não só produzem sentidos em confronto com a máquina biopolítica, mas chegam mesmo a ressignificar o espaço e o tempo, ou seja, a mesma sociabilidade, permitindo a emergência de vozes apagadas ou invisibilizadas por discursos dominantes.

Ana Carolina Cernicchiaro em "A in(corpo)ração da arte na vida e 'trice-versa': os Parangolés e o desbunde coletivo dos 60 e 70", especialmente a partir dos trabalhos de indumentária de Hélio Oiticica, pensa o corpo e suas agências no sentido de, para além de uma imunitária resistência ao contato, se configurar como algo que resiste à medida que procura o contato. Como um corpo de resistência por contato, e configurando assim o próprio âmbito público, essa arte coletiva prepara o espaço de uma comunidade por vir.

Finalizando o número, em "Encontro em carne-viva", 
Matheus Araujo dos Santos estuda Meu Corpo É Meu Protesto, Compassos do Ocaso, A Sagração de Urubutsin e Pérolas aos Porcos trabalhos performáticos produzidos conjuntamente por Sara Panamby e Filipe Espindola-, com o intuito de explorar as possibilidades diferenciais e multiplicadoras de subjetividades que esse tipo de criação encarna.

Queremos agradecer a todos os colaboradores que se dispuseram a enviar seus textos para a outra travessia, e, em especial, aos tradutores e convidados. Devemos também um agradecimento a Francisco Garamona, editor da Mansalva de Buenos Aires, que gentilmente liberou a reprodução das imagens de Max Cachimba que compõem as capas desta revista. Todos eles, e elas, prontamente se dispuseram a nos ceder seus trabalhos, fazendo com que este número fosse tão diverso quanto festivo, uma Babel de vozes que, no excessivo do seu dom, permite articular silêncios e silenciamentos que importa aprender a escutar.

Os editores 
